\title{
¿Cómo ejercen los derechos culturales las personas con discapacidad? Breve reflexión sobre la aplicación de los derechos culturales y las personas con discapacidad
}

\author{
How do people with disabilities exercise cultural rights? Brief \\ reflection on the application of cultural rights and people with \\ disabilities
}

\section{Palabras clave}

Derechos culturales, accesibilidad, discapacidad, normativa.

\section{Keywords}

Cultural rights, accessibility, disability, regulation.

\section{Introducción}

Raquel Casanovas López <uI924747@campus.udg.edu>

Este artículo se enmarca en una investigación más amplia de tesis doctoral, en la que se analiza la situación de accesibilidad cultural de las personas con discapacidad sensorial a los equipamientos culturales públicos de titularidad autonómica y municipal de una comunidad autónoma española.

El principal objetivo de este trabajo es el de reflexionar sobre si las personas con discapacidad pueden ejercer sus derechos culturales con normalidad, a pesar de la vigencia de diversa legislación que así lo exige o recomienda. Para ello, analizaremos algunas normativas en la defensa de los derechos humanos como la cultura y la discapacidad a partir de la Declaración Universal de los Derechos Humanos (I948) y otros acuerdos, y ofreceremos datos relevantes que demuestran que aún se producen deficiencias.

Partimos de la hipótesis de que una mayoría de los equipamientos culturales de España no son accesibles para todas las personas y de que las propuestas estatales e
Para citar:

Casanovas, R. (20I7): “¿Cómo ejercen los derechos culturales las personas con discapacidad? Breve reflexión sobre la aplicación de los derechos culturales y las personas con discapacidad" Revista Española de Discapacidad, 5 (2): 2I I-220.

Doi: <https://doi.org/IO.5569/23405 IO4.05.02.I2> 
internacionales no se aplican a todos los niveles administrativos.

En relación con la cultura y la necesidad de defender los derechos culturales se redactó el Pacto Internacional de Derechos Económicos, Sociales y Culturales (en adelante PIDESC) aprobado en I966 y que entró en vigor en 1976. Este espacio en el tiempo demuestra que, aunque se trata de un tratado legalmente vinculante (Black, 20IO: I 20), ha quedado relegado en cuanto a importancia por parte de los Estados, sobre todo en lo que se refiere a derechos culturales.

En cuanto a la discapacidad, también ha sido necesaria la aprobación y ratificación de distintos tratados internacionales que protegieran a las personas con discapacidad y custodiaran sus derechos. El más reciente y relevante es la Convención Internacional de los Derechos de las Personas con Discapacidad (en adelante Convención) que fue aprobada en el año 2006 y ratificada por España en el año 2008.

En la Observación General sobre el artículo 9: accesibilidad, (relativo al artículo 9 de la Convención sobre los Derechos de las Personas con Discapacidad), se detectan algunas carencias, como se puede observar en su artículo 39:

“Toda persona tiene derecho a gozar de las artes, a participar en actividades deportivas y a ir a hoteles, restaurantes y bares. No obstante, los usuarios de sillas de ruedas no pueden asistir a un concierto si para acceder a la sala de concierto solo hay escaleras. Las personas invidentes no pueden disfrutar de una pintura si no existe en la galería una descripción de la misma que puedan escuchar. Las personas sordas no pueden disfrutar de una película si esta no está subtitulada. Las personas con discapacidad intelectual no pueden disfrutar de un libro si no existe del mismo una versión de fácil lectura (...)" (Naciones Unidas. Comité sobre los Derechos de las Personas Con Discapacidad, 20I3).

Algunos de los casos planteados en el artículo anterior aún se producen en la actualidad, por lo que se puede afirmar que todavía no existe una plena inclusión que permita la total participación cultural de las personas con discapacidad. Así, se siguen vulnerando tanto los derechos culturales como los derechos de las personas con discapacidad. En un análisis de 77 equipamientos culturales de la Comunidad Autónoma de Aragón, nos encontramos que el $96 \%$ no disponen de bibliografía en braille, un $96 \%$ no dispone de libros ilustrados (donde se ofrecen además de imágenes bidimensionales en relieve, la descripción de esos contenidos y de los conceptos visuales asociados a ellos) y el $82 \%$ de los encuestados indican que el equipamiento no dispone de bibliografía en formato de lectura fácil. El mismo porcentaje $(82 \%)$ tampoco dispone de videografía en formato de subtitulado.

En el mismo estudio se detecta que el $8 \%$ no permiten el acceso de perros guía y un $3 \%$ no permite el acceso con el bastón guía y, según el artículo 5 de Ley 3/I997, de 7 de abril, de Promoción de la Accesibilidad y Supresión de Barreras Arquitectónicas, Urbanísticas, de Transportes y de la Comunicación:

"El derecho de admisión de aquellas personas que utilicen perros guía u otras ayudas técnicas que les ayuden a desenvolverse, no deberá ni podrá ser ejercido por parte de los establecimientos, alojamientos y locales de uso público por esta circunstancia”.

Estos datos evidencian el incumplimiento de la legislación vigente y que los derechos culturales y los derechos de las personas con discapacidad quedan mermados.

La principal razón por la que queremos analizar los derechos culturales de las personas con discapacidad es porque sigue siendo necesario reflexionar y considerar en qué punto nos encontramos, para comprobar si las personas con discapacidad pueden o no ejercer en igualdad de condiciones sus derechos culturales.

El incumplimiento de los derechos culturales de las personas con discapacidad, es decir, de todos sus derechos, conlleva la discriminación de este colectivo. 


\section{Concepciones históricas sobre las personas con discapacidad}

En el artículo I de la Convención, se indica que "las personas con discapacidad incluyen a aquellas que tengan deficiencias físicas, mentales, intelectuales o sensoriales a largo plazo que, al interactuar con diversas barreras, puedan impedir su participación plena y efectiva en la sociedad, en igualdad de condiciones con las demás”.

De esta definición debemos extraer algunos conceptos importantes. Por un lado, habla de personas que tengan deficiencias, no personas deficientes, por lo tanto, no califica directamente a las personas por su discapacidad. Por otro lado, habla de interactuar con diversas barreras, es decir, que está diciendo que el entorno es el que le está poniendo unas barreras o impedimentos. Además, introduce el término de participación, lo que presupone que las personas con discapacidad pueden intervenir y contribuir en la sociedad. Por último, también incluye el concepto de igualdad de condiciones con los demás, lo que significa que tienen los mismos derechos y obligaciones que cualquier otra persona.

Sin embargo, antes de llegar a esta definición de principios del siglo XXI, las personas con discapacidad han sido "categorizadas" a lo largo de la historia desde distintas perspectivas, como la de la prescindencia, la de la rehabilitación o modelo médico y la del modelo social.

En la actualidad, el modelo que prevalece -aunque convive con otros dos modelos como el rehabilitador y el de la diversidad funcional- en referencia a las personas con discapacidad, es el social. Aunque De Asís (2013: I 8-25) afirma que existen distintos argumentos que critican este modelo social. Cada uno de estos fundamentos considera a las personas con discapacidad desde distintos puntos de vista y, por lo tanto, las medidas que deben tomarse para su integración varían en función de cada una de estas ideologías o posiciones.
El desacuerdo general provoca, por lo tanto, una cierta imprecisión en los términos de la normativa que conlleva a hablar de generalidades. Debemos sumarle la convivencia de diversas leyes aprobadas en distintos períodos de tiempo que aún están en vigor, y que utilizan voces obsoletas como impedidos, minusválidos o disminuidos. En el artículo 49 de la Constitución Española, por ejemplo, se indica: "Los poderes públicos realizarán una política de previsión, tratamiento, rehabilitación e integración de los disminuidos físicos, sensorial y psíquicos, a los que prestarán la atención especializada que requieran y los ampararán especialmente para el disfrute de los derechos que este Título otorga a todos los ciudadanos" (Constitución Española, I993).

Las organizaciones que velan por los derechos de las personas con discapacidad defienden, precisamente, el concepto de persona con discapacidad (que es el término utilizado en la Convención), rechazando a su vez el concepto usado por otros movimientos y/o académicos, diversidad funcional (Agustina Palacios y Javier Romañach, entre otros, son defensores de este nuevo término surgido con el Movimiento de Vida Independiente) (Palacios, 2008: 34-37), para referirse a las personas con discapacidad. Hablamos de diversidad cultural, de personas con discapacidad y de diversidad conceptual en ambos casos que, además, evoluciona en el tiempo. Este es el principal problema.

\section{Derechos culturales}

Los derechos culturales forman parte del conjunto de los derechos humanos, es decir, podemos considerarlos como una categoría más y están a la misma altura que los derechos sociales, los políticos, los económicos y los civiles. Todos ellos fueron establecidos inicialmente en la Declaración Universal de los Derechos Humanos (I948).

Los derechos culturales fomentan la cohesión social y la paz, entre otras cuestiones, y son 
fundamentales para el reconocimiento y el respeto de la dignidad humana, que es inherente al ser humano.

Y es a través de los derechos culturales que también hay que velar por la dignidad de las personas con discapacidad, porque no pueden ejercer sus derechos en toda su plenitud ni en igualdad de condiciones que las otras personas sin discapacidad. Esto en la práctica supone una pérdida de una parte de sus derechos y en concreto de sus derechos culturales lo que conlleva, a su vez, un tipo de discriminación a este colectivo.

Las razones podrían ser dos. Por un lado, la divergencia en la conceptualización de las personas con discapacidad (según el modelo en el que se enmarque a las personas) y en consecuencia el trato hacia ellas en todos los sentidos (legislativo, social, económico, etc.). Como hemos adelantado, el modelo que se impone es el social y establece, básicamente, que las personas con discapacidad son sujetos activos que deben participar en igualdad de condiciones que cualquier persona en la sociedad. Pero no siempre pueden hacerlo porque el entorno no se lo permite. Por eso es necesario modificar el entorno. Rafael de Asís (20I3: I 8-25) explica que existen distintos argumentos que critican el modelo social lo que, sin duda, condiciona la aplicación real del término "igualdad de condiciones" y, sobre todo, en el ámbito de la cultura, que además debe velar por la conservación del patrimonio.

Por otro lado, debido al hecho de que los derechos culturales son considerados de “segunda generación”, como afirman algunos autores como Harvey (I995).

La complejidad de los derechos en sí mismos y de los derechos culturales, en particular, conlleva a una gran imprecisión de redacción. Es por ello que en el artículo 2.I del PIDESC vemos cómo se indica que los Estados deben fomentar los derechos culturales, pero solamente hasta el máximo de sus recursos y teniendo en cuenta sus propias particularidades nacionales (Naciones Unidas, I996). Además, su incumplimiento no supone una sanción, por lo que dificulta la aplicación real.

Es importante reflexionar sobre dos aspectos: el primero, la etérea concepción de la terminología utilizada y, el segundo, la imprecisión temporal establecida. ¿Qué se entiende por "progresivamente"? Entendemos que 50 años es tiempo suficiente para establecer acciones concretas y subsanar en su totalidad las carencias existentes e incluso ofrecer la formación necesaria para diseñar servicios y productos culturales accesibles a todos los públicos, entre los que se encuentran las personas con discapacidad.

No obstante, como comentábamos, también debe reflejarse el hecho de que, según la disciplina, la experiencia y el conocimiento que se tenga, el léxico y su definición es a su vez diversa. En el I congreso sobre ajustes razonables que tuvo lugar en Getafe en mayo de 2016 se concluyó que según el ámbito profesional es entendida desde una perspectiva u otra, así pues no es lo mismo lo que puede entender cómo ajuste razonable un jurista, un arquitecto o un trabajador social (MADINC: 20I6). A raíz de estas conclusiones, se estableció una línea de trabajo cuyo objetivo es la armonización del lenguaje ${ }^{\mathrm{r}}$. Hablamos de términos con matices conceptuales y su evolución en el tiempo. Este es el principal problema.

En los derechos culturales, es importante destacar que hasta I985 (20 años más tarde de la aprobación del PIDESC) no se creó el Comité de Derechos Económicos, Sociales y Culturales (Comité DESC). Se trata de un órgano de control que debía supervisar el PIDESC y comprobar que los Estados cumplían con lo acordado. Pero también era necesario crear un documento en el que basarse y por ello la Asamblea General de las Naciones Unidas aprobó en 2008 el Protocolo Facultativo.

A esta importante brecha temporal en la redacción de documentación internacional

I. Disponible en: http://www.madridsinbarreras.org/inicio-delproyecto/. 
vinculante respecto a los derechos culturales se suma la ambigüedad de los términos, la imprecisión de las obligaciones (más allá de la de respetar, proteger y cumplir estos derechos) y la libertad concedida a los Estados para que apliquen "hasta el máximo de los recursos disponibles" ${ }^{2}$.

\subsection{El artículo 15 del Pacto Internacional de Derechos Económicos, Sociales y Culturales}

Una de las partes más relevantes del PIDESC es el artículo I 5 -que toma como base el artículo 27 de la Declaración Universal de los Derechos Humanos- por su referencia al derecho a participar en la vida cultural:

“I. Los Estados Partes en el presente Pacto reconocen el derecho de toda persona a:

a) Participar en la vida cultural" (Naciones Unidas, I966).

Especial importancia adquiere el concepto "toda persona" puesto que en ella no se presupone ninguna condición, rasgo, capacidad o discapacidad. Aunque hay que tener en cuenta cuál es la relación que existe entre sociedad y persona con discapacidad en el momento de la aprobación del PIDESC, es decir: sujeto pasivo -al menos en Europa- a la que había que rehabilitar para poder integrarse en la sociedad (modelo médico o rehabilitador).

Debido a esta imprecisión y a la ambigüedad de éste artículo, entre otros, es necesaria nueva documentación internacional para reforzar lo planteado. Surgen así las Observaciones Generales, que son reflexiones realizadas por el Comité DESC sobre temas concretos ya redactados con anterioridad. Así, por ejemplo, en el año 2009 la Observación General n ${ }^{0} 2 \mathrm{I}^{3}$ -documento legalmente no vinculante-, referente al artículo I 5 , sobre todo al punto a) participar en la vida cultural, del PIDESC, supone una crítica

2. Esta afirmación se puede encontrar en el artículo 2.I. del PIDESC. Disponible en: http://www.ohchr.org/SP/ProfessionaIInterest/Pages/CESCR.aspx.

3. Disponible en: www2.ohchr.org/english/bodies/cescr/docs/ E.C.I2.GC.2I.Rev.I-SPA.doc. a esa imprecisión. En dicha observación queda reflejada también la evolución del concepto, considerándose ahora desde un punto de vista más amplio con una dimensión individual y colectiva.

\subsection{Protocolo Facultativo}

El Protocolo Facultativo del PIDESC es un mecanismo de protección de los derechos establecidos en dicho Pacto, así como una herramienta para la denuncia de los abusos realizados en los derechos económicos, sociales y culturales, y un seguimiento de la aplicación por parte de los Estados signatarios.

El primer borrador del protocolo data de I996, 30 años posteriores a la aprobación del PIDESC y 20 de su entrada en vigor, y se aprobó en 2008 . Un vez más, queda reflejada la complejidad existente para que todos los países se pongan de acuerdo en temas como los derechos culturales.

\subsection{La declaración de Friburgo}

Un año antes de la aprobación del Protocolo Facultativo del PIDESC, en 2007, un grupo internacional de trabajo surgido del Instituto Interdisciplinario de Ética y Derechos Humanos de la Universidad de Friburgo (Suiza) denominado Grupo de Friburgo elabora un documento que pretende aglutinar todos los derechos ya recogidos en otros instrumentos. Se trata de la Declaración de Friburgo que surge, tal y como se indica en la misma, para constatar la marginalización de los derechos culturales:

"En vista de la continuidad de las violaciones, del hecho de que las guerras actuales y potenciales encuentran en gran medida su germen en las violaciones de derechos culturales, y de que numerosas estrategias de desarrollo han demostrado ser inadecuadas por ignorancia de estos derechos, constatamos que la universalidad y la indivisibilidad de los derechos humanos se resienten por la marginalización de los derechos culturales” (Grupo de Friburgo, 2007: I2). 
Esta Declaración aporta mayores libertades a los individuos, una defensa más concreta de los derechos culturales, mayor pluralidad y diversidad y más concreción en las obligaciones de los Estados, así como a todos los niveles gubernamentales.

\subsection{Las expertas independientes sobre Derechos Humanos}

En el año 2009 se estableció, a través de la resolución Io/23 del Consejo de Derechos Humanos, la figura de Experta Independiente sobre Derechos Humanos, cuya finalidad es la de proteger la cultura y el patrimonio cultural, así como establecer medidas que garanticen su accesibilidad y participación (Naciones Unidas, 20I6b). Este mandato, que se inició con Farida Shaheed, se ha prorrogado en 2012 bajo la denominación de Relatora Especial en la esfera de los derechos culturales (resolución I9/6) y en 2015 . En este último año a través de Karima Bonnoune.

Las relatoras especiales Shaheed y Bonnoune han elaborado distintos informes de análisis en materia de derechos culturales, entre los que se ha incluido la perspectiva de la discapacidad, tal y como se les había pedido en sus mandatos. Shaheed se centra en esta perspectiva y así se puede ver en sus informes. Por su parte, Bonnoune explica en el párrafo I 3 de su informe $\mathrm{A} / 7 \mathrm{I} / 3 \mathrm{I} 7$ que, “(...) como ha recalcado en numerosas ocasiones la anterior Relatora Especial, el mandato en materia de derechos culturales no se ha establecido para proteger la cultura y el patrimonio cultural en sí mismo, sino las condiciones que permiten que todas las personas, sin discriminación, accedan y contribuyan a la vida cultural y participen en ella mediante un proceso de desarrollo continuo (...)" (Naciones Unidas, 20I6a).

En la redacción de este informe ya estaba aprobada la Convención Internacional de los Derechos de las Personas con Discapacidad, por lo que ya se detecta una mayor sensibilización hacia la necesidad de garantizar el acceso en igualdad de condiciones a todas las personas.
Esto se evidencia en el párrafo 65 , donde se hace especial referencia a los derechos culturales de las personas con discapacidad y a la Convención.

El párrafo I7 del mismo documento habla del principio de no discriminación y de que igualdad no significa trato idéntico en todo caso. En este punto vemos la necesidad de adaptar, si fuera preciso, lo conveniente (obra, itinerario hasta llegar al continente y al contenido cultural) para que la cultura sea accesible para todos.

La creación de un mandato independiente en la esfera de los derechos culturales, que trata este tema desde diversas áreas, confirma la necesidad de un consenso. A su vez, queda concretada la importancia de la naturalización y de que toda la sociedad conozca, entienda, comprenda y respete el hecho de que todos somos diferentes. Solo así se podrán realizar esas mejoras infraestructurales y también sociales y económicas tan necesarias para garantizar los derechos culturales.

\section{La posición de España}

A pesar de no ser una prioridad por parte de los Estados, en el caso de España, se han ido aprobando distintas leyes en relación con las personas con discapacidad, como la Ley I3/I982, de 7 de abril, de integración social de las personas con discapacidad, conocida como LISMI, la Ley 5I/2003, de 2 de diciembre, de igualdad de oportunidades, no discriminación y accesibilidad universal de las personas con discapacidad, conocida como LIONDAU, la Ley 49/2007, de 26 de diciembre, por la que se establece el régimen de infracciones y sanciones en materia de igualdad de oportunidades, no discriminación y accesibilidad universal de las personas con discapacidad o el Real Decreto Legislativo I/20I3, de 29 de noviembre, por el que se aprueba el Texto Refundido de la Ley General de derechos de las personas con discapacidad y de su inclusión social (en 
adelante Texto Refundido), que aglutina y deroga las tres leyes anteriores. En el Texto Refundido se establecen los plazos a cumplir para garantizar la plena accesibilidad.

También han surgido otras reglas que velan de manera más directa por los derechos culturales. Un ejemplo es la Ley 23/2006, de 7 de julio, por la que se modifica el texto refundido de la Ley de Propiedad Intelectual, en la que se defiende, en su artículo 3 I bis, que “(...) Tampoco necesitan autorización los actos de reproducción, distribución y comunicación pública de obras ya divulgadas que se realicen en beneficio de personas con discapacidad, siempre que los mismos carezcan de finalidad lucrativa, guarden una relación directa con la discapacidad de que se trate, se lleven a cabo mediante un procedimiento o medio adaptado a la discapacidad y se limiten a lo que ésta exige" (España, 2006: 2556I)

Otra muestra es el Real Decreto I709/20I I, de 18 de noviembre, por el que se crea y regula el Foro de Cultura Inclusiva. Este Foro, entre otras funciones, debe elaborar anualmente un informe para valorar las acciones desarrolladas y la aplicación de los objetivos estratégicos de la Estrategia Integral Española de Cultura para Todos.

A nivel internacional y también a nivel estatal se ha intensificado la aprobación de normativas a partir del 2003, año Europeo de la Discapacidad, y la aprobación de la Convención Internacional sobre los Derechos de las Personas con Discapacidad (2006) y de su ratificación, que en el caso de España fue el 3 de mayo de 2008 . Esto supone un punto de inflexión para todos los españoles y sobre todo para las instituciones públicas, por un lado, y para las personas con algún tipo de discapacidad por otro, para seguir avanzando en la aprobación de diversas leyes en materia de discapacidad.

Desde la aprobación a nivel europeo del Plan de Acción de la UE en materia de discapacidad (2003-2010), España también ha elaborado documentación a este respecto, estableciendo por ejemplo el Plan de Acción para las Personas con Discapacidad (2003-2007) o el Plan Nacional de Accesibilidad (2004-20I2), entre otros.

Además, también se han diseñado otros instrumentos, como la Estrategia europea sobre discapacidad (2010-2020) y la Estrategia española de discapacidad (20I2-2020), aprobada el I4 de octubre de 20 I I por el Consejo de Ministros a propuesta del Ministerio de Sanidad, Política Social e Igualdad, en las que se concretan y calendarizan tareas y actuaciones. Estas estrategias generales han ido configurando el esqueleto de las políticas en relación a las personas con discapacidad.

También surgieron otras estrategias más concretas como la Estrategia Integral Española de Cultura para Todos (en adelante Estrategia), implantada en 2010 por el Gobierno de España, que establece una serie de objetivos y acciones para que la cultura que se desarrolla en equipamientos dependientes del Estado sea accesible. La confluencia entre políticas sociales y culturales coincide en este punto para que los derechos culturales de las personas con discapacidad sean un hecho.

En dicho documento se indica que "en una primera fase, el ámbito de actuación de la estrategia sería el estrictamente competencial de la Administración del Estado (...). Así mismo, serán de aplicación a todas las actuaciones culturales realizadas, gestionadas o financiadas por la Administración General del Estado y las entidades citadas" (Ministerio de Sanidad, Política Social e Igualdad y Ministerio de Cultura, 20I I: 2I).

A pesar de la existencia de dicha estrategia, es decir, al tratarse de un documento cuyo cumplimiento no es obligatorio y que tan solo vincula al sector cultural estatal, seguimos encontrando equipamientos culturales autonómicos y municipales inaccesibles.

En el primer informe de seguimiento (SIIS, Centro de Documentación y Estudios, 2016) de la Estrategia, que recoge datos del período comprendido entre el año 2012 y el 20I4, 
encontramos porcentajes bajos de cumplimiento en algunos aspectos. Un ejemplo es el objetivo 7 de la Estrategia que pretende "Promover la formación en discapacidad y accesibilidad de los profesionales de la cultura y del personal de los espacios culturales para que puedan identificar y ser capaces de dar respuesta a las necesidades de las personas con discapacidad". Según se indica en este primer informe "Ni siquiera uno de cada tres organismos, apenas el 32,7\% de los organismos consultados, ha desarrollado actividades de formación en discapacidad y accesibilidad a la cultura en el período de tiempo analizado" (SIIS, Centro de Documentación y Estudios, 2016: I04). En la misma investigación sobre la realidad en Aragón comentada anteriormente, también hemos detectado porcentajes muy bajos sobre formación del personal de los equipamientos. Podemos citar algunos ejemplos: un $88 \%$ de los encuestados indican que su personal no está formado sobre legislación relacionada con la accesibilidad. El $84 \%$ de los equipamientos indican que el personal no está formado o tiene instrucciones para atender a las personas con discapacidad visual. El porcentaje de equipamientos que no dispone de personal de atención al usuario con formación para atender a personas con discapacidad auditiva aumenta a $99 \%$.

Por otro lado, el último Informe de Derechos Humanos y Discapacidad. Informe de España 2016 (Naciones Unidas, 20I7), publicado en abril de 2017 y entre los que se incluye, entre otras denuncias, la inaccesibilidad de los museos gallegos a través de un estudio coordinado desde la Universidad de Santiago de Compostela, demuestra la lejanía entre la intención de la normativa y su aplicación.

Otro ejemplo sobre la inaccesibilidad en los equipamientos culturales lo seguimos encontrando en Aragón: un 73 \% de los equipamientos públicos analizados en dicha comunidad consideran que el camino o itinerario hasta llegar a su equipamiento no está debidamente señalizado ni es accesible (semáforos sonoros, pavimento diferente, libre de obstáculos, señalización en formatos de lectura fácil, etc.) para personas con discapacidad visual y un $83 \%$ indican que dicho camino no lo es para personas con discapacidad auditiva. Es decir, el camino o itinerario no está debidamente señalizado.

Estas muestras de la realidad en diversas comunidades autónomas españolas, e incluso de equipamientos culturales estatales, confirman una vez más cómo las políticas estatales no se aplican o no se materializan ni a nivel estatal ni a nivel local.

La estrategia no obliga, pero la ley sí. En el Texto Refundido se establece como plazo máximo para el cumplimento de la accesibilidad en los edificios públicos, entre otros, el 4 de diciembre del año 2017 , por lo que podemos afirmar que no se cumple con la normativa vigente, puesto que la mayoría de equipamientos culturales, todavía hoy (finales de 20I7) no son accesibles.

\section{Conclusiones}

Los datos de diversos estudios e informes elaborados por diversas instituciones demuestran que, a pesar de la normativa que exige o recomienda, las personas con discapacidad no pueden ejercer sus derechos culturales en igualdad de condiciones que los demás ciudadanos, por lo que se sigue discriminando a este colectivo. Para que exista una plena y real participación en la vida cultural y se cumpla, por lo tanto, con lo establecido en la distinta normativa, los Estados parte deben aplicar medidas concretas contando con la participación de todos los colectivos. De igual manera, es necesario seguir trabajando para dar a conocer dicha normativa a todos los implicados y a todos los niveles administrativos y sensibilizarlos, así como a toda la sociedad para que sean conscientes del papel que deben ejercer.

A efectos de este marco normativo internacional se proponen algunas medidas para avanzar en un mayor cumplimiento de los tratados. 
- Investigar sobre las necesidades de la diversidad humana, prestando atención a las de las personas con discapacidad y contando con su opinión para contribuir en el diseño universal o diseño para todas las personas.

- Establecer y fomentar el diálogo entre investigadores, expertos de los distintos campos, artistas, gestores culturales y personas con discapacidad para buscar soluciones aplicables.

- Planificar y racionalizar mediante la creatividad para hacer posible la accesibilidad a la cultura sin distinciones.

- Establecer líneas de capacitación/formación/ sensibilización en los equipamientos culturales para modificar el concepto erróneo que existe de las personas con discapacidad y su papel en nuestro entorno.

- Naturalizar la realidad de este colectivo para ser capaces de garantizar los derechos culturales de las personas con discapacidad.
- Proteger los derechos culturales para garantizar su práctica por parte de todas las personas. Los derechos culturales están relacionados con la dignidad humana (que es inherente al ser humano).

- Fomentar el cambio de mentalidad de la sociedad en general para que las infraestructuras, servicios, productos, etc., sean accesibles para todos, teniendo en cuenta que el modelo que prevalece, a pesar de existir distintos argumentos que lo critiquen, es el social.

- Modificar el funcionamiento de los bienes, servicios y equipamientos culturales para que se adapten a los requisitos de garantizar los derechos culturales a las personas con discapacidad.

Plantearse una visión amplia del tema es imprescindible para resolver la accesibilidad cultural de las personas con discapacidad. 
Referencias bibliográficas

Black, M. (2010): Naciones Unidas: ¿ayuda o estorbo?, Barcelona: Fundación Intermon Oxfam.

Comité Español de Representantes de Personas con Discapacidad (2017): Derechos Humanos y Discapacidad. Informe España 20 I 6 (en línea). <http://www.cermi.es/sites/default/files/docs/ novedades/Informe\% 202016_ONUDEF.pdf>, acceso 8 de mayo de 2017 .

De Asís, R. (2013): Sobre discapacidad y derechos. Madrid: Dykinson.

España. Ley Orgánica 23/2006, de 7 de julio, por la que se modifica el texto refundido de la Ley de Propiedad Intelectual, aprobado por el Real Decreto Legislativo I/I996, de I 2 de abril. Boletín Oficial del Estado, 8 de julio de 2006, núm. I62. pp. 2556I.

Harvey (I995). Derechos Culturales (en línea). <http://www.ufrgs.br/difusaocultural/ adminseminario/documentos/arquivo/ Derechosculturales-harvey.pdf $>$, acceso $28 \mathrm{de}$ enero de 2015 .

MADINC. (20I6): Inicio del proyecto MADINC (en línea). <http://www. madridsinbarreras.org/inicio-del-proyecto/>, acceso 22 de agosto de 2016.

Ministerio de Sanidad, Política Social e Igualdad y Ministerio de Cultura (20I I): Estrategia integral española de cultura para todos. Accesibilidad a la cultura para las personas con discapacidad (en línea). <http://www.siis.net/ docs/ficheros/EstrategiaIntCulturaonline.pdf $>$, acceso 25 de junio de 2015 .

Naciones Unidas (2017): Derechos Humanos y Discapacidad. Informe España 2016 (en línea). $<$ www.convenciondiscapacidad.es/Informes_ new/20I6_INFORME_DDHH_DISCAP.pdf >, acceso 8 de mayo de 2017.

Naciones Unidas (2016a): Derechos Culturales (en línea). <https://www.awid.org/sites/default/files/ atoms/files/culturalrights-nI625447-es.pdf>, acceso I 4 de febrero de 2017.
Naciones Unidas (2016b): Informe de la Relatora Especial sobre los derechos culturales (en línea). <http://www.ohchr.org/SP/Issues/ CulturalRights/Pages/SRCulturalRightsIndex. aspx>, acceso I4 de febrero de 2017.

Naciones Unidas. Comité sobre los Derechos de las Personas con Discapacidad (20I3): Observación general sobre el artículo 9: accesibilidad (en línea).

<http://www.ohchr.org/Documents/HRBodies/ CRPD/GC/DGCArticle9_sp.doc $>$, acceso I I de abril de 2017.

Naciones Unidas (2008): Protocolo Facultativo (en línea) <http://www.derechoshumanos.net/ normativa/normas/2008-ProtocoloFacultativo PactoDerechosEconomicosSocialesyCulturales. htm>, acceso 28 de enero de 2015

Naciones Unidas (2006): Convención sobre los derechos de las personas con discapacidad (en línea). <http://www.un.org/esa/socdev/ enable/documents/tccconvs.pdf $>$, acceso I I de noviembre de 2016 .

Naciones Unidas (1966): Pacto Internacional de Derechos Económicos, Sociales y Culturales (en linea). < http://www.ohchr.org/SP/ ProfessionalInterest/Pages/CESCR.aspx $>$, acceso 28 de enero de 2015 .

Palacios, A. (2008): El modelo social de discapacidad. Orígenes, caracterización y plasmación en la Convención Internacional sobre los Derechos de las Personas con Discapacidad (en línea). <http://www. cermi.es/sites/default/files/docs/colecciones/ Elmodelosocialdediscapacidad.pdf $>$, acceso 3 de agosto de 2016.

SIIS, Centro de Documentación y Estudios (20I6): Informe 20I2-20I4 sobre la aplicación de la Estrategia Integral Española de Cultura para Todos (en línea). <http://www.siis.net/ documentos/ficha/52259I.pdf>, acceso $27 \mathrm{de}$ octubre de 2017. 